\title{
Co-continuous Metal-Ceramic Nanocomposites
}

\author{
Xiao Feng Zhang ${ }^{1 *}$, Gabriel Harley ${ }^{1,2}$, Lutgard C. De Jonghe ${ }^{1,2}$ \\ ${ }^{1}$ Materials Sciences Division, Lawrence Berkeley National Laboratory, \\ University of California, Berkeley, CA 94720 \\ ${ }^{2}$ Department of Materials Science \& Engineering, University of California, Berkeley, CA 94720
}

\begin{abstract}
A room temperature technique was developed to produce continuous metal nanowires embedded in random nanoporous ceramic skeletons. The synthesis involves preparation of uniform, nanoporous ceramic preforms, and subsequent electrochemical metal infiltration at room temperature, so to avoid materials incompatibilities frequently encountered in traditional high temperature liquid metal infiltration. Structure and preliminary evaluations of mechanical and electronic properties of copper/alumina nanocomposites are reported.
\end{abstract}

Keywords: Metal/ceramic nanocomposite, $\mathrm{Cu}$, porous $\mathrm{Al}_{2} \mathrm{O}_{3}$, electrochemical infiltration.

"Corresponding author. Email: xfzhang@lbl.gov 
Nanograin ceramics have been reported to exhibit dramatically increased strength, hardness, and superplasticity. ${ }^{1}$ Similarly, metallic nanowires can have unusual physical properties, such as quantized electron, photon, and phonon transport. ${ }^{2-6}$ Enhanced strength, plasticity, and hardness were also observed for nanocrystalline metals as a result of limited dislocation mobility ${ }^{1,7-11}$. While other deformation mechanisms, such as desclination activity ${ }^{12}$ may participate at high deformation rates, diffusion-controlled grain boundary sliding ${ }^{13-15}$ is likely to be the dominant deformation mechanism for nanosized grain materials. It was also reported that scale effects are significant factors in determining strength and plasticity of metals, alloys, and superalloys for sizes up to as much as several micrometers. ${ }^{16}$ When co-continuous metal/ceramic composites are created in which both the metallic and the ceramic components are of nanoscale size, the nature of the high interface/volume ratio and synergy of the combined physical properties may lead to a novel class of structural or functional materials.

To avoid materials incompatibilities associated with the elevated temperatures required for molten metal infiltration, room temperature electrochemical infiltration of porous ceramic preforms has been considered. ${ }^{17-18}$ Most published results have been for metal electrochemical infiltration of either submicron porous matrices ${ }^{18}$ or micrometer thin anodized $\mathrm{Al}_{2} \mathrm{O}_{3}$ membranes with one-dimensional nanopore channels.$^{6,17,19-20}$ The present paper describes a method in which a nanograin ceramic compact is first produced with homogeneous nanoporosity, and subsequently filled with a continuous metallic nanowire network by room temperature electrochemical infiltration.

Nanoporous alumina matrices (10 mm diameter and $1 \mathrm{~mm}$ thick, $40 \%$ porosity) were made by compacting and free sintering $20 \mathrm{~nm} \gamma-\mathrm{Al}_{2} \mathrm{O}_{3}$ nanopowder. The samples were placed in a holder, and electrochemical infiltration of $\mathrm{Cu}$ into the interconnected nanopore channels was done in a $0.2 \mathrm{M} \mathrm{CuSO}_{4}$ $+2 \mathrm{M} \mathrm{H}_{2} \mathrm{SO}_{4}+$ deionized water electroplating bath, with a $\mathrm{Cu}$ anode and the sample/Cu cathode $1.5 \mathrm{~cm}$ apart. Optimization of combined d.c. and a.c. currents was essential for efficient infiltration. The infiltrated samples were dried, and post-annealed at $500^{\circ} \mathrm{C}$ in a $\mathrm{He} / 4 \% \mathrm{H}_{2}$ atmosphere. The structure of 
the $\mathrm{Cu} / \mathrm{Al}_{2} \mathrm{O}_{3}$ nanocomposites was studied using X-ray diffraction (XRD), scanning electron microscopy (SEM), and transmission electron microscopy (TEM). Experimental details about processing of $\mathrm{Al}_{2} \mathrm{O}_{3}$ nanoporous preforms, electrochemical $\mathrm{Cu}$ infiltration, and structural characterization instruments can be found with supporting information.

Figure 1a and $1 \mathrm{~b}$ show an SEM micrograph and corresponding XRD for an as-pressed $\gamma-\mathrm{Al}_{2} \mathrm{O}_{3}$ compact, while Figure $1 \mathrm{c}$ and $1 \mathrm{~d}$ show a sintered, nanoporous $\alpha-\mathrm{Al}_{2} \mathrm{O}_{3}$ compact (58\% dense) and corresponding XRD. Complete $\gamma$-to- $\alpha$ transformation of the alumina took place during heating to $1100^{\circ} \mathrm{C}$ and holding for less than $0.5 \mathrm{hr}$, in agreement with other sintering studies on the same type of powders. $^{21}$ The particle agglomerate size in the green body ranges from 10 to $40 \mathrm{~nm}$ while after sintering the grain diameters coarsened to $80 \pm 20 \mathrm{~nm}$. Interconnected pore channels with diameters of 10 to $70 \mathrm{~nm}$ were distributed homogeneously through the sintered compacts. BET (Brunauer-EmmettTeller) analysis further demonstrated that $90 \%$ of the pore channels had diameters ranging between 20 and $65 \mathrm{~nm}$, at a specific internal surface area of $13.6 \pm 0.1 \mathrm{~m}^{2} / \mathrm{g}$.

After $\mathrm{Cu}$ infiltration, the color of the $\mathrm{Al}_{2} \mathrm{O}_{3}$ matrices changed from white to dark brown. Because XRD revealed the pure $\alpha-\mathrm{Al}_{2} \mathrm{O}_{3}$ phase and face-centered cubic $\mathrm{Cu}$ structure, the dark brown color is due to the nanoscale dimensions of the $\mathrm{Cu}^{22}$ Copper oxide reflections were absent in the XRD.

SEM and TEM examinations confirmed that $\mathrm{Cu}$ nanowires were formed inside the pore channels. A typical morphology for the $\mathrm{Cu} / \mathrm{Al}_{2} \mathrm{O}_{3}$ nanocomposites is shown in Figure $2 \mathrm{a}$, in which dark and gray image contrasts are for $\mathrm{Cu}$ wires and $\mathrm{Al}_{2} \mathrm{O}_{3}$ grains, respectively. Uniform $\mathrm{Cu}$ nanowire networks are embedded in the nanopores, with discrete interfaces between the $\mathrm{Cu}$ and the $\mathrm{Al}_{2} \mathrm{O}_{3}$, free of secondary phases, as confirmed by high-resolution TEM, Figure 2b, and by electron nanoprobe chemical analysis. Statistical measurements yielded a mean diameter of $30 \pm 9 \mathrm{~nm}$ for the $\mathrm{Cu}$ nanowires. Twinning in the $\mathrm{Cu}$ nanowires was often observed, and some twining grains extended as far as $0.9 \mu \mathrm{m}$ through the $\mathrm{Cu}$ network, indicating that the $\mathrm{Cu}$ nanowires can be single crystalline on a length scale of close to a micron, spanning several interconnected pore channels. 
Preliminary electrical property tests showed that at room temperature, the electrical resistivity throughout the $1 \mathrm{~mm}$ thickness of the samples was on the order of $10^{-6} \Omega \mathrm{m}$, confirming the continuity of the $\mathrm{Cu}$ nanowire network. Resistivity measurements were also conducted at up to $400^{\circ} \mathrm{C}$ in air. Significant departure from the low resistivity regime, due to copper oxidation, was not apparent below $150^{\circ} \mathrm{C}$.

Vickers indentation was performed on polished surfaces of nanoporous $\mathrm{Al}_{2} \mathrm{O}_{3}$ pellets and $\mathrm{Cu} / \mathrm{Al}_{2} \mathrm{O}_{3}$ nanocomposites, respectively. Figure 3 shows diamond shaped indents made with $1 \mathrm{~kg}$ load. The much shorter diagonal length for the composite indicates enhanced resistance to deformation compared with pure porous $\mathrm{Al}_{2} \mathrm{O}_{3}$. This is attributed to the $\mathrm{Cu}$ nanowire network that provides structural support for the alumina skeleton. The Vickers hardness is measured to be $7.3 \pm 0.6 \mathrm{GPa}$ for the nanocomposites, about twice as high as that for the nanoporous $\mathrm{Al}_{2} \mathrm{O}_{3}$ matrices $(3.8 \pm 0.1 \mathrm{GPa})$; the latter is consistent with the value derived from the hardness dependence equation for porous ceramics. ${ }^{23}$ Some evidences of potential toughening mechanisms, such as crack deflection by $\mathrm{Cu}$ nanowires, metal phase ductility, and crack tip blunting were also found by TEM, as shown in Figure 4.

The significance of the processing technique developed here is that the distribution, size, and connectivity of the nanowire phase may be widely varied by choice of ceramic particle size and sintering conditions. An opportunity is thus provided for the design of a variety of nanoscale structures with potential applications in MEMS, and other micromechanical or functional micro- and nano-devices. In conclusion, $\mathrm{Cu} / \mathrm{Al}_{2} \mathrm{O}_{3}$ random, co-continuous nanocomposites consisting of $\mathrm{Cu}$ nanowire/nanograin $\mathrm{Al}_{2} \mathrm{O}_{3}$ were produced at room temperature by electrochemical $\mathrm{Cu}$ infiltration of homogeneous, nanoporous alumina preforms. The $40 \%$ porosity $\mathrm{Al}_{2} \mathrm{O}_{3}$ preforms are composed of 80 $\mathrm{nm} \alpha-\mathrm{Al}_{2} \mathrm{O}_{3}$ skeleton grains with $\sim 40 \mathrm{~nm}$ diameter interconnected pores. The filling of the pore channels formed uniformly distributed, three-dimensional $\mathrm{Cu}$ nanowire networks embedded in the nanograin $\mathrm{Al}_{2} \mathrm{O}_{3}$ skeletons. The nanocomposites are electrical conductive, and hardness is doubled compared with the unfilled nanoporous alumina. 
Acknowledgment. This work was supported by the Director, Office of Science, Office of Basic Energy Sciences, Division of Materials Sciences and Engineering of the U.S. Department of Energy under Contract No. DE-AC03-76SF0098. Part of this work was made possible through the use of the National Center for Electron Microscopy facility at the Lawrence Berkeley National Laboratory. We thank Man I Lei, Rong Yu, and Paul Dearhouse for technical assistance.

Supporting Information Available: Experimental details describing processing of $\mathrm{Al}_{2} \mathrm{O}_{3}$ nanoporous preforms, electrochemical $\mathrm{Cu}$ infiltration, and structural characterization instruments. This material is available free of charge via the Internet at http://pubs.acs.org. 


\section{Figure Captions}

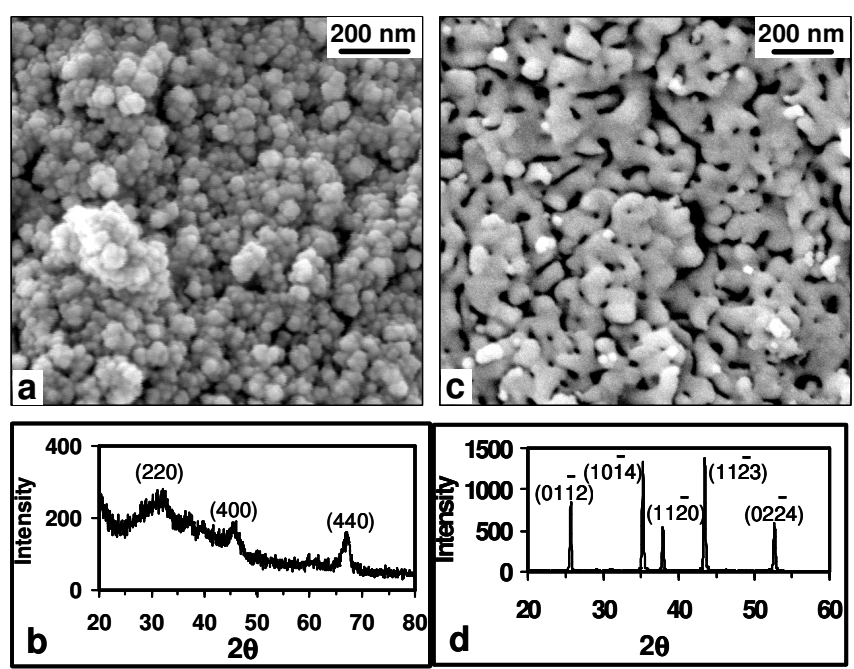

Figure 1. (a) SEM image for $\gamma-\mathrm{Al}_{2} \mathrm{O}_{3}$ nanopowder compact. Spherical nanoparticles can be seen. (b) $\mathrm{XRD}$ for the as-pressed compact after heating at $800^{\circ} \mathrm{C}$ for $24 \mathrm{hrs}$. The peak indices are consistent with the $\gamma-\mathrm{Al}_{2} \mathrm{O}_{3}$ phase. The broadening of the XRD peaks is indicative of nanoparticles. (c) SEM image taken from a fractured surface of a sintered compact. $\mathrm{Al}_{2} \mathrm{O}_{3}$ nanograins and interconnected nanopore channels are observed. (d) XRD for a compact sintered at $1100^{\circ} \mathrm{C}$. The peak indices agree with the $\alpha$ $\mathrm{Al}_{2} \mathrm{O}_{3}$ phase.

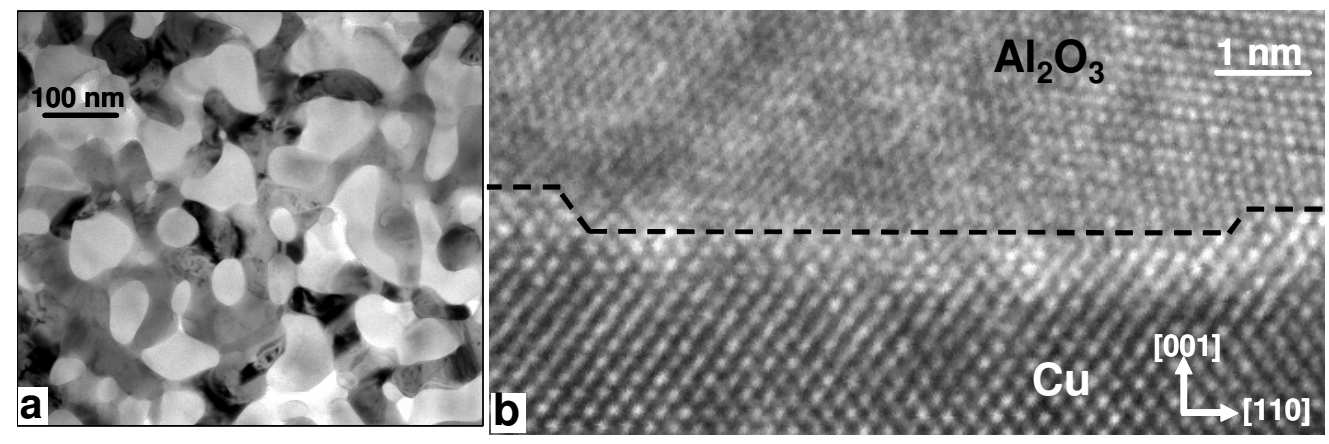

Figure 2. (a) TEM bright-field image showing microstructure of a $\mathrm{Cu} / \mathrm{Al}_{2} \mathrm{O}_{3}$ nanocomposite. The $\mathrm{Al}_{2} \mathrm{O}_{3}$ nanograins appear gray, and the $\mathrm{Cu}$ nanowires appear dark. A uniformly distributed $\mathrm{Cu}$ nanowire network is evident. (b) High-resolution TEM image showing a $\mathrm{Cu} / \mathrm{Al}_{2} \mathrm{O}_{3}$ interface (marked by a dashed line). The interface is smooth at the atomic level, and free of secondary phases. 

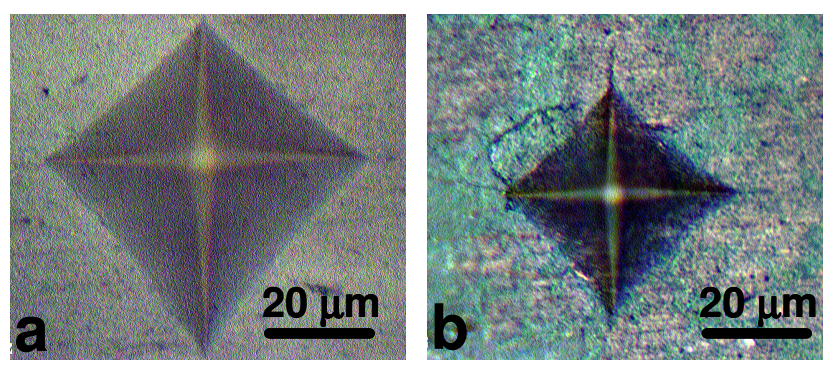

Figure 3. Vickers indents on (a) a nanoporous $\mathrm{Al}_{2} \mathrm{O}_{3}$ compact, and (b) a $\mathrm{Cu} / \mathrm{Al}_{2} \mathrm{O}_{3}$ nanocomposite. The much shorter diagonal length in (b) corresponds to a remarkably enhanced deformation resistance of the nanocomposites compared with $\mathrm{Al}_{2} \mathrm{O}_{3}$ matrices.

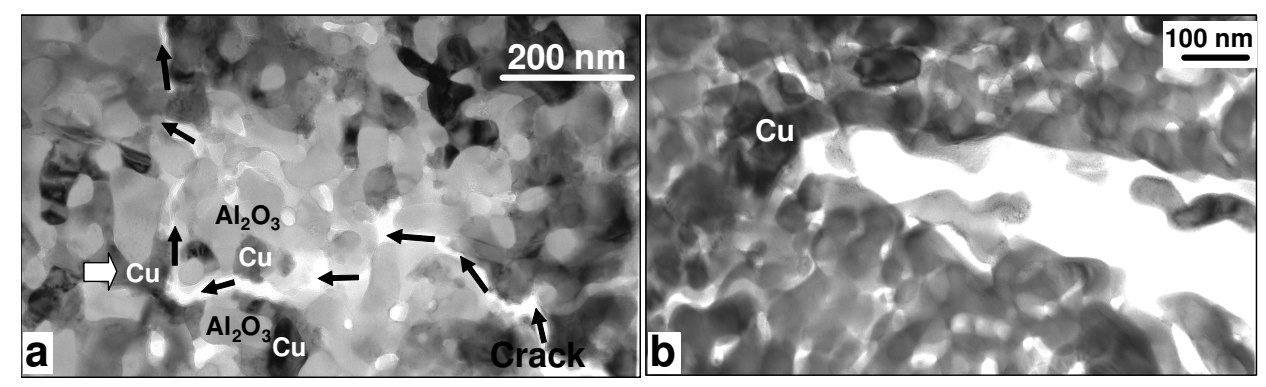

Figure 4. TEM images of (a) Crack propagation through the nanocomposite, along $\mathrm{Al}_{2} \mathrm{O}_{3} / \mathrm{Al}_{2} \mathrm{O}_{3}$ and $\mathrm{Cu} / \mathrm{Al}_{2} \mathrm{O}_{3}$ interfaces. Note the strong crack deflection at the arrowed $\mathrm{Cu}$ ligament. (b) Crack tip blunting at $\mathrm{Cu}$ ligament. 


\section{References}

(1) Weertman, J.R.; Farkas, D.; Hemker, K.; Kung, H.; Mayo, M.; Mitra, R.; Van Swygenhoven, H. MRS Bulletin 1999, 24, 44-50.

(2) Muller, C.J.; van Ruitenbeek, J.M.; de Jongh, L. J. Phys. Rev. Lett. 1992, 69, 140-143.

(3) Van Houten, H.; Beenakker, C.W.J. Physics Today 1996, 7, 22-27.

(4) Kouwenhoven, L.P.; Venema, L.C. Nature 2000, 404, 943-944.

(5) Schwab, K.; Henriksen, E.A.; Worlock, J.M.; Roukes, M.L. Nature 2000, 404, 974-977.

(6) Zhang, Z.; Sun, X.; Dresselhaus, M.S.; Ying, J.Y.; Heremans, J. Phys. Rev. B 2000, 61, 4850-4861.

(7) Nieh, T.G.; Wadsworth, J. Scripta Metall. Mater. 1991, 25, 955-958.

(8) Sanders, P.G.; Eastman, J.A.; Weertman, J.R. Acta Mater. 1997, 45, 4019-4025.

(9) Yip, S. Nature 1998, 391, 532-533.

(10) McFadden, S.X.; Mishra, R.S.; Valiev, R.Z.; Zhilyaev, A.P.; Mukherjee, A.K. Nature 1999, 398, 684-686.

(11) Lu, L.; Sui, M.L.; Lu, K. Science 2000, 287, 1463-1466.

(12) Murayama, M.; Howe, J.M.; Hidaka, H.; Takaki, S. Science 2002, 295, 2433-2435.

(13) Van Swygenhoven, H.; Derlet, P.M. Phys. Rev. B 2001, 64, 224105-224109.

(14) Van Swygenhoven, H. Science 2002, 296, 66-67.

(15) Schiøtz, J.; Jacobsen, K.W. Science 2003, 301, 1357-1359.

(16) Uchic, M.D.; Dimiduk, D.M.; Florando, J.N.; Nix, W.D. Science 2004, 305, 986-989.

(17) Searson, P.C. Solar Energy Materials and Solar Cells 1992, 27, 377-388.

(18) Hirata, Y.; Kyoda, K.; Hatano, H. Mat. Lett. 1994, 21, 155-159.

(19) Saito, M.; Kirihara, M.; Taniguchi, T.; Miyagi, M. Appl. Phys. Lett. 1989, 55, 607-609.

(20) Yin, A.J.; Li, J.; Jian, W.; Bennett, A.J.; Xu, J.M. Appl. Phys. Lett. 2001, 79, 1039-1041. 
(21) Ahn, J-P.; Park, J-K.; Lee, H.-W. NanoStructured Materials, 1999, 11, 133-140.

(22) Liz-Marzan, L.M. Materials today 2004, 2, 26-31.

(23) McColm, I.J. Ceramic Hardness, Plenum Press: New York, 1990; p 8. 